\title{
Proper Use of Social Networks to benefit Patient Care
}

\author{
Peter J. Papadakos, MD, FCCM, FAARC \\ Director of Critical Care Medicine, University of Rochester
}

As an individual who writes and lectures on the impact of technology and in interactions in our society at large and in medical professionalism specifically, I have been quoted as to the negative impact of social networks which in many respects can act as a distraction. There is a large literature in both the lay media and professional literature on how practitioners may be distracted from patient care by surfing social media during clinical duties. The University of Rochester Modified CAGE tool has verified that an addictive behavior may be triggered by the use of personal electronic devices (PED's). ${ }^{(1)}$ However, I have never been an advocate to ban technology in medicine but to train physicians and health workers how to properly use technology to help their patients and modulate personal use in clinical areas.

This excellent article by Kun Liu and others, ${ }^{(2)} \mathrm{Ce}$ rebral Circulation and Ischemia: How to monitor it during surgery, is a clear illustration of how clinicians and scientists from opposite ends of the globe can use social media technology to enhance international medical collaboration. Such conferences done on the net and then the publications that they generate can bring cutting edge medical science to the bedside in a rapid manner. Doing such social media conferences has a more marked advantage over the traditional manner of organizing a meeting at a fixed site, then for some, travelling a great distance at a great expense and then a number of revisions of the meeting notes over a prolonged period of time until the information is shared. Social media conferences are rapidly organized. Participation requires only a computer or a smartphone and has no extra costs of travel can be broader in participation and can be shared rapidly and in many cases in real time. Health care practitioners should strive to develop more such programs. Not only do they enhance medical knowledge, but also act as cornerstones to educate health practitioners in the proper use of technology. This education will go far in illustrating what social media's place is in the practice of medicine, a tool, not a distraction.

Address for correspondence: Peter J. Papadakos, MD, FCCM, FAARC, Director of Critical Care Medicine, University of Rochester, Rochester, New York 14642

Email: peter_papadakos@urmc.rochester.edu

\section{Disclosure of Funding}

None

Additional publication details

Journal short name: Transl Perioper \& Pain Med

Received Date: January 4, 2015

Accepted Date: January 5, 2015

Published Date: January 5, 2015

Transl Perioper \& Pain Med 2015, 2 (1):1

Editor

Renyu Liu, MD, PhD, Director of Preoperative Medicine, Department of Anesthesiology and Critical Care, Perelman School of Medicine at the University of Pennsylvania, 336 John Morgan building, 3620 Hamilton Walk, Philadelphia, PA 19104 Email: liu@uphs.upenn.edu

\section{Citation and Copyright}

Citation: Papadakos PJ. Proper Use of Social Networks to benefit Patient Care. Transl Perioper \& Pain Med 2015, 2 (1): 1

Copyright: (C) 2015 Papadakos PJ, MD. This is an open-access article distributed under the terms of the Creative Commons Attribution License, which permits unrestricted use, distribution, and reproduction in any medium, provided the original author and source are credited.

\section{References}

1. Papadakos PJ. The Rise of Electronic Distraction in Health Care is Addiction to Devices. J Anesth. Clinic Res 2013;4.

2. Liu K, Liu H, Gad WD, and Meng L. Cerebral Circulation and Ischemia: How to monitor it during surgery. Transl Periop \& Pain Med, 2015:2 (1);2-8. 